\title{
Study on Relation between Equity Structure and Performance of Listed Companies - Evidence for Building Industry in A Share Market
}

\author{
Xinyuan Zhang ${ }^{1}$, Zhixiu Guo ${ }^{1}$, Xiaorui Feng ${ }^{1} \&$ Yan $\mathrm{He}^{1}$ \\ ${ }^{1}$ Finance Department of International Business School, Jinan University, Zhuhai, China \\ Correspondence: Xinyuan Zhang, Finance Department of International Business School, Jinan University, \\ Qianshan Road 206\#, Zhuhai City, Post No 519070, Guangdong Province, China. Tel: 86-158-2057-8156. \\ E-mail: zhangxinyuan1995@126.com
}

Received: April 23, 2017

doi:10.5539/ijef.v9n7p114
Accepted: May 6, 2017

Online Published: June 15, 2017

\begin{abstract}
The equity structure is the basis for corporate governance, and the decisive factor for performance of listed companies. Considering the return on equity as the measure index of company performance, the paper has collected 2014-2016 data related to index of equity structure from 32 listed companies in Shanghai and Shenzhen, made descriptive statistical analysis and correlation analysis on it with spass 20.0 statistical software, and discussed the relation between equity structure and performance of listed companies. The research finds that: Chinese listed companies for building industry still have relatively high equity concentration, imperfect internal governance mechanism and poor equity restriction. The effect of "bargaining" is difficultly developed to promote the growth of performance. China shall further strengthen the efforts to control, spur listed companies to reinforce the internal management, and optimize the equity structure to ensure the effective balance, with the purpose of accelerating the healthy and sustainable development of listed companies and safeguarding the interests of medium-small investors.
\end{abstract}

Keywords: Chinese building industry, equity structure, equity concentration, equity restriction, company performance

\section{Introduction}

The equity structure is the main factor affecting the allocation of control right and governance efficiency of companies. Based on the review of research literatures on equity concentration, equity restriction and company performance, the research collected 2014-2016 data related to index of equity structure from 32 listed companies in Shanghai and Shenzhen by considering the return on equity as the measure index of company performance, made descriptive statistical analysis and correlation analysis on it with spass 20.0 statistical software, discussed the relation between equity structure and performance of listed companies, and summarized the influence of equity structure features of Chinese listed companies for building industry on company performance, which provides the specific data and theory reference for relevant policies prepared by Chinese government, the deepening of reform on equity allocation, the optimization of equity structure of listed companies for building industry and the improvement of business performance.

\subsection{Literature Overview}

The relation between equity structure and company performance has been the focus of academic circles at home and abroad. A great number of theoretical and empirical research results have also been producedand are mainly manifested in two aspects, one of which is the relation between equity concentration and company performance, while the other of which is whether the equity restriction may improve the company performance.

\subsubsection{Research on Relation between Equity Concentration and Company Performance}

The research on relation between equity concentration and company performance has been early made in western developed countries. For example, as early as 1933, Berle and Means (1933) wrote the book named Modern Corporation and Private Property, in which the relation between equity structure and company performance was researched. Their research has found that: the same direction relation is provided between equity concentration and company performance, and as the equity of the enterprise is highly concentrated, there is consistency between the shareholder benefit and enterprise value. Shareholders will tend to strengthen the 
supervision of management layer for their own benefits. However, the extremely dissipative structure will lead to the lack of effective supervision on the management layer; consequently, the abuse of power and serious issues on "entrustment of agent" affecting the company performance will be caused. Schleifer et al. (1986) have made a relevant research and also found that the controlling shareholder and minority shareholder would be partnership for interests with the rising of equity, accordingly, both of whom actively and jointly supervise the management layer, so as to reduce the problem of "free riding" in management layer for highly dispersive equity and improve the company performance. The empirical research on the relation between equity structure and company performance by Claessens (1995) also shows that the interactional relation exists between equity concentration and stock price. The more concentrated equity structure becomes, the higher the stock price is; while higher stock price will further lead to the company's equity concentration. Shieifer et al. (1986) hold an opinion that when listed companies maintain a certain equity concentration, shareholders are more likely to actively supervise behaviors of the management layer for interests, so as to minimum the problem of "free riding" in the company and reduce the agent cost of the management layer for the promotion of company value. In consideration of endogenous possibility of equity structure, Jensen (1983) has researched the relation between holding quantity of internal manager and company performance in terms of nature, and it is found that the relation between holding quantity of internal manager and company performance presents a negative correlation. The increase of share holding rate of internal manager actually could not drive the growth of company performance; instead, it would reinforce the control of insider on the company, which will affect the company management and decline the company performance.

The securities market in China develops relatively late, however, the research on the relation between equity structure and company performance has also produced a lot of research results and empirical findings. For example, Su Wukang (2003) made a regression analysis on changes of equity concentration of Chinese listed companies during 1998-2001 and has found that the correlation between the shareholding proportion of the first majority shareholder and company performance is positive, while that between such proportion of the following majority shareholder and company performance is negative, which indicates that the equity structure of listed companies has counterbalance relation. Jin Xuefei et al. (2005) have empirically analyzed the equity concentration of listed companies and enterprise performance with Tobin's $Q$ value, and it is shown that the equity concentration is in directly proportion to company performance. Li Jinsheng (2008) studied the mining, electricity, gas, wholesale and retail trade industries and concluded that in the listed companies within competitive industries, the ownership concentration of major shareholders was beneficial to the improvement of corporate performance. While on the other hand, in the listed companies within monopoly industries, higher ownership concentration was conducive to the improvement of corporate performance which had nothing to do with the shareholders. Li Ping (2016) selected 2575 enterprise samples from 2005 to 2013 as the research object, and concluded that the relative holding ownership concentration was beneficial to the improvement of the company's operating performance, the control right proportion of the actual controller and the company's operating performance presented positive U type relation. Wang Cheng and Cui Yue (2017) took private enterprises as an example and concluded that the ownership concentration and internal control quality both had a positive effect on corporate performance and part of the impact of ownership concentration on corporate performance was achieved through the mediating role of internal control quality.

\subsubsection{Research on Relation between Equity Restriction and Company Performance}

The research on company performance from the perspective of equity restriction is an important direction of researches at home and abroad. The research suggests that the equity restriction can effectively solve the agency problem in the operation of the company and improve the efficiency of the company. For example, with the research of Berler and Means (2001), it is believed that the dispersive equity structure of the company easily leads to the goal incompatibility between shareholder and manger, and the minority shareholder cannot supervise and restrict manager; consequently, the power is corrupted and the interests of shareholder will be damaged.

This view actually implies two hypotheses including that the more the dispersive the company's equity is, the worse the company performance becomes, and the more concentrated the company's equity is, the higher the company performance becomes.

Demsetz (1983) holds that equity structure is the way for shareholders to maximize the interests, and the mutual gamble among shareholders could generate the most optimal and balanced equity structure. However, the equity structure is an endogenous variable decided by the performance, and logically has no effect on the performance. Therefore, the equity structure is irrelevant with company performance. The results of Pctroni, Nagar and Wolfenzon (2000) show that the equity restriction is conductive to the improvement of company performance, and the performance of company characterized with dispersive and balanced equity structure is higher than that 
of company with the sole majority shareholder. The reason is the mutual supervision among shareholders with comparative holdings which effectively prevent majority shareholders from abusing the power and embezzling company interests and improve the company performance.

In the research of Shi Donghui (2000), He found that in a listed company with 1-3 majority shareholders, the behavior of the first majority shareholder is subject to other shareholders, which possibly safeguards shareholders' interests from being infringed and effectively executes the profit goal of the company. The empirical results of Huang Yuxiang et al. (2003) show that the equity restriction could restraint possible predation of the sole majority shareholder, and protect the interests of investors. With the research, Chen Xinyuan et al. (2004) found that Tobin's Q value and P/B ratio of the company with equity restriction are significantly higher than those of company without restriction. Chen Deping and Chen Yongsheng (2011) studied the influencing factors of impact of ownership concentration and the equity restriction ratio on corporate performance of SME listed companies. The results showed that the equity restriction ratio could help improve corporate performance. Zhu Desheng and Zhang Feifei (2016) studies manufacturing listed companies from 2010 to 2013, and concluded that the higher the equity restriction ratio, the more effective the internal control; the higher the equity control, the better the corporate performance.

The above researches have consistent positive opinion on equity restriction in the company governance, but some differences also exist. For example, with the research of Zhu Hongjun (2004) on discussion of Hongzhi Equity, it is found that the "closely-held" equity restriction structure is not more efficient than the structure of "the sole majority shareholder". The research of Zhao Jingwen et al. (2005) also shows that the excessive equity restriction will affect the operating performance of listed companies, and the performance of company with equity restriction structure is not higher than that of company with the sole majority shareholder which has same industry and similar total asset size. Such conclusion has also been confirmed by the empirical results of Xu Liping et al. (2006).

\subsection{Research Hypothesis}

\subsubsection{Research Hypothesis on Relation between Equity Concentration and Company Performance}

There are different views for the relation between equity concentration and company performance and the influence of such concentration on performance. Some believe that the high equity concentration will have the positive influence on the company performance, while others hold the opposite view that the equity concentration will have the negative influence on the company performance.

Based on this, the paper puts forward the following hypotheses with the compromise method:

H1: The shareholding proportion of the first majority shareholder is negatively correlated with company performance;

H2: The shareholding proportion of the top ten shareholders is negatively correlated with company performance;

H3: The quadratic sum of shareholding proportion of the top five shareholders is positively correlated with company performance;

\subsubsection{Research Hypothesis on Relation between Equity Restriction Degree and Company Performance}

Wolfenzon (2000), Gomes and Novaes (2005) thinks that the perfect equity restriction structure possibly generates the bargaining effect", and effectively develops an incentive mechanism and supervision mechanism to ensure the efficient operation of the company and promote the growth of company performance. Pctroni (2000) also considers that when the company equity is concentrated on more than two shareholders and their shareholding proportions are comparative, the mutual supervision and mutual restriction among these shareholders could balance the internal power relation of the company, and prevent majority shareholder from abusing the power and embezzling the company interests to improve the company performance. Based on this theory, it is assumed in the paper that the majority shareholders easily abuse the power and embezzle the company interests in a situation where the company equity is relatively dispersive and the shareholding proportions of shareholders are not high; therefore, the follows could be obtained:

H4: The equity restriction has positive effect on company performance.

\section{Method}

\subsection{Sample Selection and Data Sources}

Collect and select 2014-2016 panel data of listed building enterprises in Shanghai and Shenzhen with Great Wisdom Software and East Money Net, and those companies with data missing, ST and *ST companies shall be 
rejected. Process the data collected with Spass20.0 statistical software.

\subsection{Measurement Criteria for Equity Restriction}

Many indexes and algorithms are available to measurement of equity restriction. For example, Laportaetal measured it with critical value by selecting $20 \%$ as the judgment limit, and Comes et al. made the regression analysis on data by setting two index values of $20 \%$ and $10 \%$. However, most of the researches calculate and analyze it based on $\mathrm{CNn}$ and $\mathrm{Z}$ indexes. In the paper, the $\mathrm{Z}$ index is used to calculate and analyze the mechanism of equity restriction through shareholding proportion among shareholders. $\mathrm{Z}$ index could better define the control ability of the first majority shareholder over the company. The specific calculation is shown as the formula (1):

$$
Z=\frac{\text { Shareholding proportion of the first majority shareholder }}{\text { Shareholding proportion of the second majority shareholder }}
$$

When $\mathrm{Z}$ index in the formula is greater, it shows that the power difference between the first majority shareholder and the second majority shareholder is larger, and the equity restriction degree is higher.

\subsection{Measurement Criteria for Equity Concentration}

The use of CRn index and Herfindahl index is a quantitative method to evaluate the equity concentration.

(1) CRn index refers to the sum of shareholding proportions of the top $\mathrm{N}$ majority shareholders among all shareholders of the listed sample company, and the formula is as follows:

$$
\mathrm{CR}^{1}=\text { the shareholding quantity of the first majority shareholder / total equity }
$$

$$
\mathrm{CR}^{5}=\text { the shareholding quantity of the top five majority shareholders / total equity }
$$

$$
\mathrm{CR}^{10} \text { = the shareholding quantity of the top ten majority shareholders / total equity }
$$

Where, $\mathrm{CR}^{1}, \mathrm{CR}^{5}$ and $\mathrm{CR}^{10}$ are respectively the shareholding proportions of the first majority shareholder, the top five shareholders and the top ten shareholders.

(2) The Herfindahl index is referred to as the $\mathrm{H}$ index, which refers to the quadratic sum of shareholding proportions of the top $n$ majority shareholders of the company. For example, H5 and H10 are respectively the quadratic sum of shareholding proportions of the top five shareholders and that of the top ten shareholders. The calculation formula is as follows:

$$
H \mathrm{n}=\sum_{\mathrm{i}=1}^{\mathrm{n}} \mathrm{s}_{\mathrm{i}}^{2}
$$

In the formula, $\mathrm{S} i$ is expressed as the shareholding proportion of the $i^{\text {th }}$ majority shareholder of the company, and $\mathrm{n}$ is the number of majority shareholder to be calculated. The value of $\mathrm{N}$ in the existing literature ranges between 3 and 10. The paper selects the quadratic sum of the shareholding proportions of the top five shareholders and that of the top ten shareholders to measure the equity concentration, and:

$$
\begin{aligned}
& H 5=\sum_{i=1}^{5} s_{i}^{2} \\
& H 10=\sum_{i=1}^{10} s_{i}^{2}
\end{aligned}
$$

\subsection{Measurement Criteria for Company Performance}

Performance evaluation is the comprehensive evaluation and interpretation on the operating result and development capability of the company with the specific index system based on some evaluation standards and a certain procedure. There are many methods and models to evaluate the performance of listed companies, and these methods and models will not be presented here. The paper selects the method for return on equity (ROE) of index commonly used for company performance to analyze the company performance, and the formula as shown in formula (8):

$$
\text { Return on equity }=\frac{\text { Net profit }}{\text { Net asset at the end of year }} \times 100 \%
$$

In the formula, ROE refers to the return on shareholder's equity, which is obtained by dividing the after-tax profit of the company by net asset, and is the percentage between net profit and average shareholder's equity. Such index could objectively reflect the income level of shareholders' equity, and measure the efficiency of the company. When the index value is higher, it indicates the income from the investment will be higher.

\subsection{Control Variable Selection}

The company performance is affected by various factors, and to draw more accurate conclusions, combined with the research results of other scholars at home and abroad, the asset-liability ratio (LEV) is selected as the control variable. 


\section{Results}

\subsection{Descriptive Statistical Analysis}

Based on 2014-2016 data processed of 32 Chinese listed companies for building industry, the paper analyzes the equity structure from the two aspects including equity concentration and equity restriction.

\subsubsection{Descriptive Statistical Analysis on Equity Concentration}

Table 1. Descriptive statistical table on equity concentration

\begin{tabular}{llcccc}
\hline Equity concentration & Year & Minimum & Maximum & Mean & Standard deviation \\
\hline \multirow{3}{*}{ CR1 } & 2014 & 0.2985 & 0.8474 & 0.5711 & 0.1431 \\
& 2015 & 0.2887 & 0.8352 & 0.5815 & 0.1285 \\
& 2016 & 0.0568 & 0.8251 & 0.5405 & 0.1958 \\
CR5 & 2014 & 0.3649 & 0.8546 & 0.7005 & 0.1217 \\
& 2015 & 0.5298 & 0.8754 & 0.6953 & 0.1112 \\
& 2016 & 0.0645 & 0.8926 & 0.6531 & 0.2001 \\
CR10 & 2014 & 0.3799 & 0.8879 & 0.7138 & 0.1091 \\
& 2015 & 0.5394 & 0.9289 & 0.7141 & 0.1241 \\
H5 & 2016 & 0.0836 & 0.9014 & 0.6671 & 0.1960 \\
& 2014 & 0.1316 & 0.7013 & 0.3873 & 0.1637 \\
H10 & 2015 & 0.1697 & 0.6808 & 0.3628 & 0.1394 \\
& 2016 & 0.0034 & 0.6808 & 0.3485 & 0.1827 \\
& 2014 & 0.1418 & 0.7113 & 0.3873 & 0.1637 \\
& 2015 & 0.1699 & 0.5708 & 0.3731 & 0.1393 \\
\hline
\end{tabular}

From the above table, it can be seen that Chinese listed companies for building industry all have relatively high equity concentration for there are a large number of private enterprises in the sample selection. The maximums of the first majority shareholder and the top five and the top ten shareholders are up over $70 \%$, and the maximums of their quadratic sums are also over 50\%. Although in the view of trend, the shareholding proportions of the first majority shareholder and the top five and the top ten shareholders descends year by year, the existing data show that majority shareholders are still in absolute control position, which indicates that Chinese listed companies for building industry have the relatively high equity concentration and the phenomenon of sole majority shareholder is still the main factor possibly affecting the company performance.

\subsubsection{Descriptive Statistical Analysis on Equity Restriction}

Table 2. Descriptive statistical analysis on equity restriction

\begin{tabular}{lccccc}
\hline Equity restriction & Year & Minimum & Maximum & Mean & Standard deviation \\
\hline \multirow{2}{*}{$\mathrm{Z}$} & 2014 & 0.0033 & 0.9205 & 0.2150 & 0.2989 \\
& 2015 & 0.0031 & 0.9409 & 0.1923 & 0.2666 \\
& 2016 & 0.0029 & 0.9409 & 0.1920 & 0.2595 \\
\hline
\end{tabular}

The empirical results above show that $\mathrm{Z}$ value is negatively correlated with company performance. The restriction of the second majority shareholder on the first majority shareholder is relatively weak, and the maximum of it is only 0.9205 , which is almost same every year. The mean of $\mathrm{Z}$ is about 0.2 , which shows that the restriction of the second majority shareholder on the first majority shareholder is very weak. This indicates that the research hypothesis 4 where the equity restriction has negative effect on company performance is effective.

\subsection{Correlation Analysis}

For the research on equity structure and company performance of Chinese listed companies for building industry, if the correlation between variables is extremely high, the multi-collinearity problem will simultaneously exist in 
the regression equation. Therefore, before the research, it is necessary to analyze the correlation between variables of equity structure and company performance, so that the influence on regression result could be avoided. Results of the correlation test between variables are shown as Table 3

Table 3. Analysis on correlation structure between variables of equity structure and company performance

\begin{tabular}{llcccccccc}
\hline & ROE & CR1 & CR5 & CR10 & Z & H5 & H10 & LEV \\
\hline \multirow{2}{*}{ ROE } & Pearson correlation & 1 & .257 & .292 & .308 & .249 & .250 & .015 & $-.400^{*}$ \\
& Significance (bilateral) & & .187 & .131 & .111 & .201 & .200 & .929 & .035 \\
CR1 & Pearson correlation & .247 & 1 & $.829^{* *}$ & $.832^{* *}$ & $.967^{* *}$ & $.965^{* *}$ & $-.432^{*}$ & -.317 \\
& Significance (bilateral) & .186 & & .000 & .000 & .000 & .000 & .018 & .101 \\
CR5 & Pearson correlation & .293 & $.827^{* *}$ & 1 & $.989^{* *}$ & $.810^{* *}$ & $.810^{* *}$ & .084 & -.216 \\
& Significance (bilateral) & .131 & .000 & & .000 & .000 & .000 & .670 & .269 \\
CR10 & Pearson correlation & .308 & $.826^{* *}$ & $.999^{* *}$ & 1 & $.803^{* *}$ & $.803^{* *}$ & .081 & -.230 \\
& Significance (bilateral) & .111 & .000 & .000 & & .000 & .000 & .682 & .239 \\
& Z Z & .249 & $.966^{* *}$ & $.810^{* *}$ & $.803^{* *}$ & 1 & $1.000^{* *}$ & -.362 & -.306 \\
& Significance (bilateral) & .201 & .000 & .000 & .000 & & .000 & .058 & .113 \\
\multirow{2}{*}{ H5 } & Pearson correlation & .252 & $.966^{* *}$ & $.810^{* *}$ & $.803^{* *}$ & $1.000^{* *}$ & 1 & -.362 & -.306 \\
& Significance (bilateral) & .201 & .000 & .000 & .000 & .000 & & .058 & .113 \\
\multirow{2}{*}{ H10 } & Pearson correlation & .015 & $-.442^{*}$ & .084 & .081 & -.362 & -.362 & 1 & .287 \\
& Significance (bilateral) & .937 & .018 & .670 & .682 & .058 & .058 & .139 \\
\multirow{2}{*}{ LEV } & Pearson correlation & $-.401^{*}$ & -.317 & -.216 & -.230 & -.306 & -.306 & .287 & 1 \\
& Significance (bilateral) & .036 & .101 & .269 & .239 & .113 & .113 & .139 \\
\hline
\end{tabular}

Note. * Significant correlation at the levels (bilateral) of 0.05 ; ** Significant correlation at the levels (bilateral) of .01; c. list N=32.

From the above table, we can see that the significant correlation exists between CR1, CR5, H5 and ROE. However, the positive correlation and negative correlation are presented between CR10, H10 and Z. It is shown that the effect of the first majority shareholder on company performance is negative; the quadratic sum of shareholding proportions of the top five majority shareholders is positively correlated with company performance, and the positive correlation and negative correlation are presented between the shareholding proportions of the top ten majority shareholders and company performance. Therefore, it is considered that the shareholding proportions of the top ten majority shareholders all are not correlated with the company performance, and such conclusion supports $\mathrm{H} 1$ and $\mathrm{H} 2$, but $\mathrm{H} 3$ is inconsistent, which indicates that the increase of proportion of tradable share could optimize the equity concentration to a certain extent, and is conductive to company governance; then, the company performance is possibly improved.

\section{Discussion}

\subsection{Research Conclusions}

Considering ROE as the measure index of company performance, the paper has collected 28 listed companies in Shanghai and Shenzhen as the research objects, and 2014-2016 data on index of equity structure of 32 listed companies in these two cities, so as to analyze it in terms of descriptive statistics and correlation and discuss the relation between equity structure and company performance of listed companies. The conclusion is shown as follows:

1). The results of the descriptive statistics analysis on equity concentration show that Chinese listed companies for building industry have relatively high equity concentration. Firstly, the maximums of the first, the top five and the top ten majority shareholders are up over $70 \%$, and the maximums of their quadratic sums are also over $50 \%$. It is indicated that majority shareholders are still in absolute control position, and such phenomenon of sole majority shareholder is still the main factor possibly affecting the company performance.

2). The results of descriptive statistical analysis on equity restriction show that the restriction of the second majority shareholder on the first majority shareholder is relatively weak, and the maximum of it is only 0.9205 ; the mean of $\mathrm{Z}$ index is about 0.2 , and it is basically same within three years, which shows that the internal governance mechanism of Chinese listed companies for building industry is imperfect, and the restriction of the second majority shareholder on the first majority shareholder is very weak. Such conclusion indicates that the hypothesis 4 where the equity restriction index has negative effect on company performance is effective. 
3). With the correlation analysis between equity structure and company performance, it is found that: the significant correlation exists between CR1, CR5, H5 and ROE. However, the positive correlation and negative correlation are presented between CR10, H10 and Z. It is shown that the effect of the first majority shareholder on company performance is negative; the quadratic sum of shareholding proportions of the top five majority shareholders is positively correlated with company performance, and the positive correlation and negative correlation are presented between the shareholding proportions of the top ten majority shareholders and company performance. Therefore, it is considered that the shareholding proportions of the top ten majority shareholders all are not correlated with the company performance, and such conclusion supports $\mathrm{H} 1$ and $\mathrm{H} 2$, but $\mathrm{H} 3$ is inconsistent, which indicates that the increase of proportion of tradable share could optimize the equity concentration to a certain extent, and is conductive to company governance; then, the company performance is possibly improved.

\subsection{Suggestions}

1). The existing research results show that: in the case of high equity concentration of the company, the company's equity structure imbalance might lead to sole majority shareholder, which will endanger the efficient operation of the company. Therefore, under the such situation where Chinese listed companies for building industry has serious problem of "sole majority shareholder", China shall further intensify the control, spur listed companies to reinforce the internal governance, optimize the equity structure as soon as possible, and ensure the effective restriction of rights, with the purpose of overall good operation of listed companies and protection of interests of medium-small investors.

2). The solid evidence finds that: the mean of $Z$ of the top five and the top ten majority shareholders of listed companies is about 0.2 within three years for the restriction of such shareholders on the first majority shareholder is relatively weak, which indicates that the internal governance mechanism of Chinese listed companies for building industry is imperfect, and the equity restriction index of listed companies is negatively correlated with the company performance. Based on this, the efficient operation and the improvement of company performance might be guaranteed only by appropriately increasing the proportion of tradable shares and weakening the power of majority shareholders.

3). The existing research theory proves that: the efficient internal governance is required for growth of performance of listed companies, and the optimization of equity structure could fundamentally improve the effect of companies' internal governance. With the correlation analysis between equity structure and company performance of 32 listed companies for building industry, it is found that the effect of the first majority shareholder on company performance is negative; the quadratic sum of shareholding proportions of the top five majority shareholders is positively correlated with company performance, and the positive correlation and negative correlation are presented between the shareholding proportions of the top ten majority shareholders and company performance on account of possible low company governance level. Such conclusion exactly presents that many problems have existed in terms of governance of Chinese listed companies for building industry, and the effect of "bargaining" is difficultly developed to promote the growth of performance. Therefore, it is suggested that the listed companies should further strengthen the internal equity structure reform, so as to improve the company performance with the equity structure.

\section{References}

Cheng, W., \& Yue, C. (2017). A Study on the Impact of Ownership Concentration on Performance in China's Private Listed Companies - An Empirical Analysis Based on the Intermediary Effect of Internal Control Quality. Friends of Accounting. https://doi.org/10.3969/j.issn.1004-5937.2016.15.009

Dajiang, W. (2011). Empirical research on relations between capital structure and enterprise value in construction industry. Commercial Times. https://doi.org/10.3969/j.issn.1002-5863.2011.34.054

Demsetz, H. (1983). The structure of ownership and the theory of the firm. The Journal of Law and Economics, 26(2), 375-390. https://doi.org/10.1086/467041

Deping, C., \& Yongsheng, C. (2011). Research on the Relationship between Ownership Concentration, Equity Restriction and Corporate Performance. Accounting research. https://doi.org/10.3969/j.issn.1003-2886.2011.01.007

Desheng, Z., \& Feifei, Z. (2016). Internal Control Effectiveness, Equity Check and Balance and Corporate Performance. Friends of Accounting. https://doi.org/10.3969/j.issn.1004-5937.2016.02.020

Fama, E. F., \& Jensen, M. C. (1983). Separation of ownership and control. The Journal of Law and Economics, 26(2), 301-325. https://doi.org/10.1086/467037 
Gengyin, L., \& Ling, Y. (2010). Empirical research of capital structure and profitability of small medium enterprises: Data comparison and analysis before and after being listed of small and medium-sized enterprises based on SME board. Industrial Economic Review. https://doi.org/10.14007/j.cnki.cjpl.2010.01.017

Guoliu, H., \& Guozhou, J. (2004). Ownership structure, company management and company performance-New evidence from China listed companies. Finance and Trade Research.

Holderness, C. G., Kroszner, R. S., \& Sheehan, D. P. (1999). Were the good old days that good? Changes in managerial stock ownership since the great depression. The Journal of Finance, 54(2), 435-469. https://doi.org/10.1111/0022-1082.00114

Jinsheng, L., Linbang, F., \& Shanqi, P. (2008). Analysis of industrial characteristics of relations between ownership concentration and business performance in listed company. Chinese Public Administration. https://doi.org/10.3782/j.issn.1006-0863.2008.02.020

Leech, D., \& Leahy, J. (1989). Ownership structure, control type classifications and the performance of large british companies. Warwick Economics Research Paper, 101(409), 1418-1437.

Liping, X., Yu, X., \& Gongmeng, C. (2006). Ownership concentration, check-and-balance of ownership and influence on business performance. Economic Research.

Ping L. (2016). An Analysis of the Impact of Ownership Structure of Listed Companies on Business Performance. "Decision and Information" Magazine. Economics and Management School of Peking University.

Pivovarsky, A. (2003). Ownership concentration and performance in ukraine's privatized enterprises. IMF Economic Review, 50(1), 10-42.

Souleles, N. (1999). The response of household consumption to income tax refunds. American Economic Review, 89(89), 947-958. https://doi.org/10.1257/aer.89.4.947

Ting, L. (2012). Empirical analysis of relations between company capital structure and performance in construction industry. Financial Supervision.

Torben, P., \& Steen, T. (1999). Economic and systemic explanations of ownership concentration among Europe's largest companies. International Journal of the Economics of Business, 6(3), 367-381. https://doi.org/10.1080/13571519984133

Xiangbo, N., \& Yating, J. (2011), Empirical analysis of capital structure of listed company in power industry based on SPSS. Research of Finance and Accounting.

\section{Copyrights}

Copyright for this article is retained by the author(s), with first publication rights granted to the journal.

This is an open-access article distributed under the terms and conditions of the Creative Commons Attribution license (http://creativecommons.org/licenses/by/4.0/). 